\title{
Imaginarios y chilenización: los agentes fiscales chilenos y su visión del espacio y la población andina de la provincia de Tarapacá, norte de Chile 1880-1918/*
}

\author{
Imaginaries and Chilenization: Chilean State Agents \\ and their Vision of the Andean Space and Population \\ of the Tarapacá Province, Northern Chile 1880-1918
}

\section{Luis Castro Castro}

Universidad de Valparaíso, Chile

En la década de 1880 el estado chileno incorpora a su soberanía la provincia de Tarapacá, desatando un complejo proceso denominado chilenización. En este contexto, los agentes fiscales chilenos comenzaron a desplegar dispositivos políticos, económicos y culturales enfocados en asentar con rapidez la nueva administración, como el hacer de este territorio y su población parte integral de la nación chilena. Bajo estos términos, en este artículo se describen y analizan los imaginarios que construyeron estos agentes sobre el espacio y la población andina de la provincia de Tarapacá entre fines del siglo XIX y comienzos del XX.

PALABRAS ClaVE: Imaginarios; Representación; Espacio andino; Población andina; chilenización.

In the 1880's, the Chilean state annexed the province of Tarapaca into its jurisdiction. This gave rise to a complex process known as chilenization. In this context, Chilean state officials implemented political, economic and cultural devices with the purpose of establishing rapidly the new administration, and transforming this territory and its population into a part of the Chilean nation. Consequently, this article describes and analyzes the imaginary of the Andean space and population, belonging to the Tarapaca province, created by these state agents between the late nineteenth and the early twentieth century.

KEYwords: Imaginaries; Representation; Andean space; Andean population; Chilenization.

* Este artículo forma parte del proyecto Fondecyt 1100060 «Agentes fiscales, poblaciones indígenas y sociedad regional: articulaciones y conflictos durante el proceso de chilenización (AricaTacna y Tarapacá, 1880-1930)». 


\section{Introducción}

La guerra del Pacífico provocó, al triunfar Chile sobre Perú y Bolivia, que todo el actual territorio del Norte Grande chileno (Antofagasta, Tarapacá y Arica) pasara a ser, siguiendo la tipología de Frederick Turner enunciada a inicios de la década de 1890, una frontera sujeta a un desafío de conquista, ${ }^{1}$ lo que para Rajchenberg y Héau-Lambert fue el sustento de un típico propósito expansionista estatal de la segunda mitad del siglo XIX. ${ }^{2}$ En este contexto, la entonces provincia de Tarapacá dio cuenta de un territorio fronterizo polifuncional al contener dinámicas de conformación de los límites espaciales (las especificaciones administrativas de los bordes principalmente) como de readecuación de los componentes culturales (las formas de vida y las prácticas religiosas de matriz andino-colonial por ejemplo) a razón del proceso mismo de apropiación y de los requerimientos discursivos de legitimación. ${ }^{3}$ Bajo estos términos, se desató un campo (interacciones y conflictos) de posibilidades entre un frente de expansión operado por los intereses estatales chilenos en búsqueda de la soberanía y una frontera en movimiento sostenida por los constantes - fluidos y traumáticos- reacomodos sociales, económicos y políticos de los sujetos que residían en esta región como de los que habían arribado o estaban llegando a habitarla atraídos por la riqueza salitrera. ${ }^{4}$

Lo que comenzará a estar en juego en la provincia de Tarapacá a partir de la década de 1880, será la búsqueda estatal chilena por encontrar una representación del lugar y sus residentes que sintetizara su ideal nacional en un escenario que remarcaba sociológica y culturalmente lo diverso, es decir, por un lado la penetración de lo chileno mediante dispositivos institucionales (leyes, reglamentos, órdenes, cárceles, hospitales, escuelas, etc.) $\mathrm{y}$, por otro, las resistencias operadas desde las practicas cotidianas (el trabajo, la sociabilidad, las fiestas, etc.) que soportaban lo étnico (aymaras),

1 Turner, 1996 [1893]. Para un análisis sugerente sobre la problematización de la frontera de (y a partir de) los planteamientos de Frederick Turner ver Jiménez, 2001 y Brenna, 2011. La noción de agencialidad, en este caso, sigue los planteamientos de Prakash, 1997.

2 Rajchenberg y Héau-Lambert, 2007, 37-61.

3 El concepto de territorio fronterizo polifuncional ha sido tomado de Valcuende y Cardia, 2009.

4 Según Valcuende y Cardia, 2009, los frentes de expansión están asociados a procesos de ocupación efectiva de territorios en función de intereses económicos, una característica que, asociada a la condición fronteriza, desata la existencia de una «frontera en movimiento» a razón de loa trajines humanos que terminan condicionando, conflictuando o reforzando la demarcación política. 
lo nacional no chileno (peruanos y bolivianos) y lo migrante (obreros, empleados y comerciantes chinos, europeos, argentinos y aquellos venidos desde el Norte Chico y la zona central de Chile, entre otros). Consecuentemente, en Tarapacá se activará una pugna asimétrica de dominación/subordinación entre el imaginario nacional traído por los agentes estatales chilenos de matriz homogenizadora y los imaginarios de las poblaciones locales y migrantes soportadoras de condiciones heterogéneas. Como nos alerta Mariana Giordano, siguiendo a Bronislaw Baczko, el imaginario es un lugar estratégico donde se manifiestan conflictos sociales y mecanismos de control a razón de buscar forzadamente consolidar una identificación colectiva con una idea de nación. ${ }^{5}$ De este modo, la voluntad por construir una nación de ciudadanos unidos en la identificación de referentes comunes (lo simbólico) se ligará fuertemente con una ideología territorial que conllevará la búsqueda de un espacio nacional (lo físico). ${ }^{6}$ Será, en efecto, mediante la imposición fáctica y legal de un nuevo territorio nacional (chileno y soberano) que se desplegará el modo de asimilar, incluso contener a ratos, la heterogeneidad residente en la desértica provincia de Tarapacá. ${ }^{7}$

En el caso particular de este artículo, nos abocaremos a describir como los agentes fiscales chilenos operaron, edificaron, sostuvieron y problematizaron la representación del espacio y la población andina, una otredad que alteraba y, en ocasiones, ponía en cuestionamiento los afanes y los parámetros chilenizadores de civilización y modernización. ${ }^{8}$ Es decir, como se construyó una imagen de la ruralidad andina y de los indígenas y mestizos que habitaban en ella a efecto de, por una parte, justificar y consolidar la soberanía chilena como, por otra, validar los rasgos sistémicos de su quehacer administrativo orientado a los componentes que sostenían la industria salitrera, el leit motiv de la guerra del Pacífico y de la ocupación por parte de Chile de lo que era, hasta ese entonces, el extremo sur del Perú.

5 Giordano, 2009, 1283-1284.

6 Quijada, 2000, 373-374.

7 Susana Bandieri, 2009, 1-5, señala que en el caso de sur argentino fue esta articulación, es decir una nación que controla un territorio definido por fronteras, la que visibilizó el estado-nacional. La «nacionalización» del estado, entonces, implicó el avance de las distintas formas de ejercicio del poder sobre nuevos (conquistados por antonomasia) espacios.

8 Respecto al proceso de chilenización de las provincias de Tarapacá y Arica y sus componentes de civilización y modernización revisar Castro y Rivera, 2011, 271-300; Díaz, 2006, 296-310; Díaz, Ruz y Mondaca, 2006, 215-235; González, 2002. 


\section{El contexto: espacio, administración y demografía}

La región de Tarapacá orográficamente está conformada por tres macro-zonas en dirección poniente-oriente: a) el borde costero y la cordillera de la Costa (entre los 0 y $800 \mathrm{msnm}$ ); b) la depresión intermedia o pampa (con una altitud promedio de $1.000 \mathrm{msnm}$ ); y c) la pre-cordillera, altiplano y cordillera de los Andes (entre los 2.000 y $5.000 \mathrm{msnm}$ ). Si bien las dos primeras son las más pobres en recursos hídricos, a partir de la segunda mitad del siglo XIX cobijaron un sostenido crecimiento poblacional provocado por la industria minera del salitre, una dinámica que se consolidó durante el siglo XX a pesar del término del ciclo salitrero a fines de la década de 1920. En tanto la tercera enmarca el área andina, siendo la sierra o pre-cordillera (entre los 2.000 a $3.800 \mathrm{msnm}$ ) un lugar dominado por valles transversales donde se ubican la mayoría de los pueblos y caseríos dedicados a la agricultura, y el área cordillerana (sobre los $3.800 \mathrm{msnm}$ ) un espacio dominado por las altas cumbres (que en algunos casos alcanzan los $5.000 \mathrm{msnm}$ ) y la altiplanicie (con un promedio de $4.000 \mathrm{msnm}$ ) con sus pequeños ríos, lagunas y pastizales.

Sus límites, en el presente como a fines del siglo XIX y comienzos del XX, son por el norte la región de Arica-Parinacota (antiguo departamento de Arica) siguiendo el trayecto del valle de Camarones, por el sur la región de Antofagasta demarcado en parte por el cauce del río Loa, por el oeste el océano Pacífico y por el este la línea divisoria con Bolivia (ver mapa).

Entre los años 1879 y 1883 la fuerzas chilenas de ocupación administraron el hasta ese entonces departamento peruano de Tarapacá en calidad de territorio anexado, ${ }^{9}$ una condición que terminó con su cesión a perpetuidad en el tratado de paz firmado con el Perú el 20 de octubre de $1883 .{ }^{10}$ Habiéndose incorporado cabalmente toda esta zona a la soberanía chilena, el 31 de octubre de 1884 se crea por ley la provincia de Tarapacá, ${ }^{11}$ intensificando y consolidando el reordenamiento administrativo orientado a con-

9 Parte importante de esta fuerza de ocupación estuvo compuesta por funcionarios administrativos y expedicionarios, como Alejandro Bertrand y Francisco Vidal Gormaz, dedicados a recabar antecedentes geográficos, económicos y sociales a objeto de viabilizar la instalación administrativa chilena.

10 Villalobos, Silva, Silva y Estellé, 1976, 591.

11 Archivo Nacional de Chile (ANC), Fondo Intendencia de Tarapacá (AIT), 48, Iquique 2 de diciembre de 1884 . 


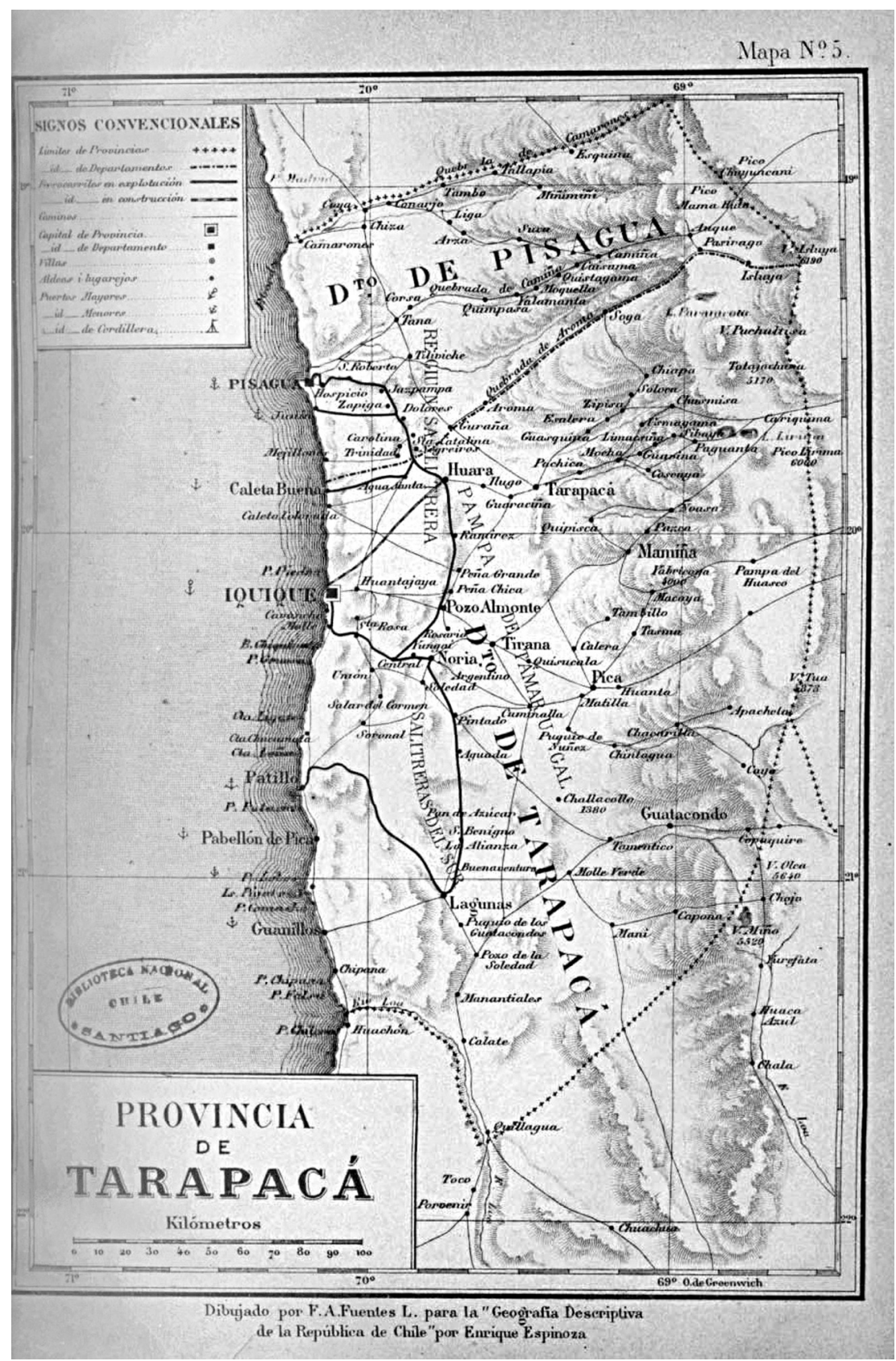


solidar la chilenización de sus parajes y habitantes. Esta nueva provincia, a cargo de un intendente, ${ }^{12}$ congregó dos departamentos (el de Tarapacá y Pisagua), siendo el segundo administrado por un gobernador ${ }^{13}$ trece subdelegaciones bajo la responsabilidad de subdelegados en cada una de ellas, y por cuarenta y tres distritos tutelados por inspectores. A su vez cada subdelegado tuvo como colaboradores un inspector de subdelegación, un juez de subdelegación y un juez de distrito.

El departamento de Pisagua, con su cabecera administrativa en el puerto homónimo, fue subdivido en tres subdelegaciones, dos urbanas (Pisagua y Santa Catalina) y una rural (Camiña). En tanto el departamento de Tarapacá, con sus dependencias principales en el puerto de Iquique, se seccionó en diez subdelegaciones, ocho urbanas (El Ferrocarril, Aduana, Escuela Domingo Santa María, Huantajaya, Caleta Buena, Patillos, Pozo Almonte y La Noria) y dos rurales (Pica y Tarapacá).

En lo que toca al área andina, tipificada como rural en la nueva nomenclatura administrativa, la subdelegación de Camiña quedó conformada por los distritos de Camarones, Camiña y Aroma; la subdelegación de Pica a su vez abarcó los distritos de Pica, Canchones y Guatacondo; y la subdelegación de Tarapacá tuvo los distritos de Mamiña y Tarapacá. ${ }^{14}$

Tres años más tarde, a mediados de 1887, el departamento de Tarapacá se amplió de 10 a 13 subdelegaciones, dos de ellas destinadas a dar cuenta del quehacer fiscal asociado a los cantones salitreros y la tercera motivada por la activación del mineral argentífero de Challacollo. ${ }^{15}$ Esta última subdelegación adscribió a su jurisdicción administrativa el distrito de Guatacondo.

Esta organización determinó entre las décadas de 1880 y 1930 tres rasgos fundamentales: 1) la conformación administrativa del espacio tarapaqueño en dos grandes áreas: la urbana (donde estaban los puertos y las

12 Antes que se creara la provincia de Tarapacá, la máxima autoridad recaía en el jefe político, cargo que por lo general fue ocupado por un militar o marino de alto rango.

13 El objetivo de crear la figura de la gobernación civil para administrar el departamento de Pisagua se debió a la necesidad del aparato estatal chileno radicado en esta provincia de generar un mecanismo que le permitiera a la administración de este pedazo del territorio tarapaqueño no depender de manera inoficiosa de las autoridades instaladas en Iquique, las que estaban a una distancia considerable tomando en cuenta los medios de transporte de la época. Por su parte el departamento de Tarapacá lo tendrá a cargo el intendente con la ayuda de un administrador departamental.

14 ANC, AIT, 56, Santiago 17 de noviembre de 1884; ANC, AIT, 56, Santiago 18 de noviembre de 1884; ANC, AIT, 68, Iquique 21 de julio de 1884.

15 ANC, AIT, 110, Iquique agosto 1887. 
oficinas y pueblos ubicados en la pampa salitrera ${ }^{16}$ ) y la rural (constituida por el espacio andino de oasis, valles precordilleranos y altiplano donde estaban los campesinos peruanos y bolivianos y los indígenas); 2) la predominancia de la primera respecto a la segunda por consideraciones económicas, políticas y sociales; y 3) que el conjunto de los funcionarios fiscales chilenos, salvo los inspectores y jueces de distrito, se posicionaran de manera distante al área andina. ${ }^{17}$

Para fines de la década de 1880 el aparato fiscal chileno en Tarapacá estaba conformado por algo más de 50 funcionarios de rango menor (secretarios, actuarios, ayudantes, etc.), unos 10 de rango medio adscritos a la aduana, tesorería, registro civil, notaría y posta de correo y telégrafos, los cuales residían en su gran mayoría en los puertos de Iquique y Pisagua y los menos en los pueblos pampinos de Pozo Almonte, Huara y La Noria. A estos se sumaban los 49 inspectores de distrito, siendo apenas 10 los asignados a las dependencias rurales, empleados estos últimos que por lo general serán residentes destacados (indígenas y mestizos de nacionalidad peruana y boliviana) de las localidades precordilleranas y altiplánicas al no haber disposición por parte de chilenos a ocupar estos cargos por encontrarse alejado de la pampa y la costa donde se generaba la riqueza salitrera. ${ }^{18}$ En tanto la planta ejecutiva la componían 18 autoridades: un intendente, un gobernador y dieciséis subdelegados.

La burocracia fiscal chilena finalmente se completaba con los policías y los gendarmes de las cárceles públicas, los que tampoco eran muchos y además estaban mal equipados, sobre todo los adscritos a las subdelegaciones rurales. Prueba de lo anterior son las reclamaciones cursadas por los subdelegados de Tarapacá y Challacollo a la máxima autoridad de la provincia los años 1894, 1895 y 1903 de no disponer o tener apenas dos policías a pie para resguardar un territorio extenso y agreste, y la información remitida el año 1916 por el juez de la subdelegación de Camiña a sus superiores de la obligación que tuvo de liberar a un individuo detenido por

16 Oficinas salitreras se les llamaba a aquellos recintos urbanizados donde estaban las instalaciones para extraer y procesar el salitre, las dependencias administrativas y las habitaciones de todos los trabajadores, una suerte de company-town. En estas oficinas regían los reglamentos de las empresas dueñas de las estacas calicheras. Los pueblos, en cambio, aglutinaban a la población residente en la pampa no vinculada a las compañías salitreras y que se dedicaban, por lo general, a prestar servicios a las instalaciones industriales. Fue en los pueblos donde se ubicaron las reparticiones fiscales.

17 Castro, 2008, 224-228.

18 Este último tema y sus alcances es tratado en Castro, 2012, 101-111. 
robarle al cura por no disponer de un policía y de un recinto adecuado para estos propósitos. ${ }^{19}$

Por último, estaban los empleados de los municipios de Iquique, Pisagua y Pica que tenían una jurisdicción estrictamente local y que bordeaban en su totalidad un poco más de treinta individuos.

Respecto a los antecedentes demográficos de la zona andina en el período, los primeros registros datan de 1885 por parte de las máximas autoridades provinciales indicando que la población rural del departamento de Tarapacá alcanzaba a los 5.022 habitantes y la del departamento de Pisagua a los 3.610 residentes, ${ }^{20}$ algoritmos que sufrirán un alza en el informe oficial del censo levantado en noviembre de 1885 - y publicado un año más tarde - al establecer que los residentes rurales llegaban a los 6.957 en el departamento de Tarapacá y 5.372 en el de Pisagua. ${ }^{21}$ Este mismo censo, el primero realizado por Chile en todos los territorios del extremo norte bajo su soberanía y tutela después de la guerra del Pacífico, contabilizaba en 45.086 la población total de la provincia.

En 1892 nuevos reportes del intendente y del gobernador de Pisagua ratificarán el incremento de la población rural andina. De acuerdo a estas autoridades los residentes en la pre-cordillera y el altiplano alcanzaban a las 13.710 habitantes, 7.031 en el departamento de Tarapacá y 6.679 en el de Pisagua, ${ }^{22}$ una tendencia que se verá validada por los resultados del censo de 1895 que contabilizará un número total de 14.658 moradores en las subdelegaciones andinas, 13.370 en el departamento de Tarapacá y 1.288 en el de Pisagua, ${ }^{23}$ siendo el total provincial de 89.751 personas.

Este aumento poblacional, sin embargo, se detuvo a comienzos del siglo XX. Es así como el censo de 1907 contabilizó en apenas 8.678 individuos la población rural andina, 6.377 en el departamento de Tarapacá y 2.301 en el de Pisagua, ${ }^{24}$ con un total en toda la provincia de 110.036; y el censo de 1920 en 6.561 los lugareños andinos, 4.518 en el departamento de Tarapacá y 4.043 en el de Pisagua, pasando a representar apenas un 6,52\% del total provincial que llegaba a $100.553 .{ }^{25}$

19 Castro, 2012, 123-129.

20 ANC, AIT, 291, Iquique abril 1885; ANC, AIT, 74, Pisagua 19 de noviembre de 1885.

21 Oficina Central de Estadísticas, 1886, 804.

22 ANC, AIT, 249, Iquique junio 1892; ANC, AIT, 242, Pisagua 1 de julio de 1892.

23 Oficina Central de Estadísticas, 1900, 7.

24 Comisión Central del Centro, 1908, 41-42 y 52-53.

25 Dirección General de Estadísticas, 1925, 9-10. 


\section{La representación del espacio andino tarapaqueño: territorio, soberanía y chilenización}

El territorio no es un dato, sino una construcción social e histórica que se articula y sostiene a través de representaciones intencionadas y tensionadas. ${ }^{26}$ En los mismos términos, según Joan Nogué «son las acciones y los pensamientos humanos los que dan sentido a una porción cualquiera del espacio y la convierten en territorio», más aún, el «territorio, per se, no existe, sino que se hace». ${ }^{27}$ Coincidente con estas ideas, para Carla Lois el territorio es un «conjunto de representaciones que organizan la experiencia social y son constitutivas de ciertas prácticas», pero además estas «representaciones son múltiples, variadas $\mathrm{y}$, a veces, paradójicas». ${ }^{28}$

No obstante lo diversas que puedan llegar a ser las representaciones del espacio a efecto de conformar un territorio, el grueso de ellas tienden a institucionalizarse en ciertos dominios de validez buscando ser asimiladas e internalizadas por diferentes grupos. ${ }^{29}$ Por lo mismo, la producción y circulación de significados y re-significados pasa a ser una práctica compleja de objetivación del espacio, pero también de los sujetos que moran en él y de sus costumbres y creencias. Bajo estos parámetros, la incorporación de la provincia tarapaqueña a la administración chilena a inicios de la década de 1880 ocurrió tanto mediante prácticas institucionalizadas que tuvieron por orientación asegurar el dominio territorial, como a través de prácticas de representaciones interesadas en construir una geografía nacional del lugar. ${ }^{30}$

Según Nelson Martínez, José Luis Martínez y Viviana Gallardo, la inclusión de los grupos indígenas y el espacio andino a una nueva historia nacional no sólo fue consecuencia de la guerra del Pacífico y de los cambios territoriales a partir de ella, sino también de un «proceso mucho más profundo que implicó la transformación de lo que hasta ese momento se pensaba como lo nacional y, con ello, de un imaginario país». ${ }^{31}$ En efecto, a partir de la conquista e incorporación de la Araucanía y el desierto

26 Rajchenberg y Héau-Lambert, 2007, 41.

27 Nogué, 1998, 60. Este autor y sus ideas de la construcción cultural de territorio se encuentra en Quijada, 2000, 377.

28 Lois, 1999, sin páginas.

29 Idem.

30 Las categorías de «prácticas institucionalizadas» y de «prácticas de representaciones» son propuestas y desarrolladas por Lois, 1999, sin páginas.

31 Martínez, Martínez y Gallardo, 2003, 198 y 201. 
de Atacama durante la década de 1880 la fisonomía de un Chile $\sin$ indios - porque estaban afuera de la frontera interna en el sur y afuera de la frontera externa en el norte- derivó irremediablemente a uno con indios, obligando a re-imaginar la nación y su composición espacial.

Ante esta nueva dimensión de la nación, la burocracia estatal chilena trató de bosquejar e ilustrar para sí misma una determinada representación de los espacios, territorios, poblaciones y riquezas, componentes todos muy necesarios para operar y hacer posible el control administrativo. ${ }^{32}$ Para el caso particular de las provincias de Tarapacá y Antofagasta, los ya mencionados N. Martínez, J. L. Martínez y V. Gallardo sostienen que en este ejercicio de bosquejar, ilustrar y tratar con la población y el espacio andino la burocracia chilena no tuvo un modelo propio sino hasta entrado el siglo XX, reproduciendo las divisiones administrativas y los aparatos de control heredados del Perú y Bolivia. Si bien para estos autores una evidencia que respalda su planteamiento fue la tardía exigencia (recién durante el primer decenio del siglo pasado) a los residentes de la región de Atacama ${ }^{33}$ para que optaran entre la nacionalidad chilena y la boliviana o peruana, ${ }^{34}$ nuestro parecer es que esta tesis se debilita ostensiblemente como una explicación general si consideramos que en la provincia de Tarapacá tal procedimiento ocurrió tempranamente entre los años 1885 y 1887 y en la de Tacna-Arica se dilató, al punto de no ejecutarse, hasta la firma del tratado de 1929. En estos términos, nuestro planteamiento es que los agentes fiscales chilenos asentados en los territorios (conquistados e incorporados) del extremo norte desde un comienzo configuraron - tanto en su quehacer cotidiano como mediante los lineamientos programáticos- una representación del espacio y los sujetos andinos con el objeto de afianzar y expandir el control administrativo, representación contenida en un nacionalismo hilvanado desde la década de $1830^{35}$ y sustentada en los parámetros de civilización y modernización enunciados con fuerza entre fines de la década de 1870 y comienzos de la de $1880 .{ }^{36}$

En este marco, el uso de ciertos dispositivos y mecanismos heredados de las administraciones peruana (principalmente) y boliviana (en menor

32 Ibidem, 199.

33 En este caso no hacemos referencia a la actual división político-administrativa de Chile, sino al espacio andino de la entonces provincia de Antofagasta.

34 Martínez, Martínez y Gallardo, 2003, 199.

35 Ver Cid, 2011.

36 Castro, 2012. 
medida) para resolver inconvenientes o aplicar disposiciones se acotó a un recurso meramente funcional y no regular que tuvo por propósito central el optimizar la inversión estatal - en otras palabras gastar poco y complicarse lo menos posible - en lugares (el área andina) y en relación a poblaciones (indígenas y campesinos) poco relevantes para los intereses estratégicos de Chile centrados en la industria y la renta salitrera que se materializaba y operaba entre la pampa y la costa. ${ }^{37}$

La primera autoridad política chilena de Tarapacá, Patricio Lynch, explicitará meridianamente a mediados de 1880 esta mirada al señalarle al ministro de educación que las escuelas debían abrirse en las ciudades de la costa y en los pueblos de la pampa salitrera a razón de que únicamente en estas locaciones era posible acercar «naturalmente [los] elementos de nacionalidades diversas que forman la gran mayoría de las poblaciones de este territorio» y donde «concluirán por chilenizarse los criollos». ${ }^{38}$ Cuatro años más tarde, el intendente Gonzalo Bulnes reafirmará lo indicado por Lynch al establecer que el servicio administrativo o judicial no podía ser concejil en el espacio andino ya que en él «no vive un solo chileno». ${ }^{39}$

A partir del posicionamiento que comenzó a ejercer el estado chileno en la provincia de Tarapacá a comienzos de la década de 1880, las autoridades de ocupación se orientaron a afianzar tres tareas básicas: desmantelar la burocracia peruana con el objeto de provocar un rápido cambio de administración política; procurar la pronta normalización de la explotación salitrera; y llevar a cabo una política de modernización amparado en un espíritu misional y civilizador. ${ }^{40}$ Para el caso de Tarapacá, esto último implicó que el estado chileno mediante un modelo de desarrollo concordante con los intereses de la oligarquía y un aparato fiscal en expansión transitara rápidamente de una ocupación física del territorio a un dominio estratégico de éste, especialmente del espacio en donde se encontraban los yacimientos salitreros (la pampa) y donde se podía sacar esta producción (la costa y sus puertos). ${ }^{41} \mathrm{Al}$ amparo de lo anterior, operó en el ejercicio

37 La relación entre rentismo salitrero y las prioridades estatales chilenas en lo político y lo económico se aborda en Castro, 2005.

38 ANC, AIT, 1, Iquique, 17 de julio de 1880.

39 ANC, AIT, 67, Iquique, 5 de junio de 1884.

40 Los objetivos de las primeras autoridades chilenas de Tarapacá están extensamente descritos en Pinto, 1985, 107-127, y Castro, 2008.

41 Castro, 2005, 11-57. 
estatal chileno una concepción cultural del espacio tarapaqueño y de los sujetos residentes en él condicionada por lo económico como por una práctica administrativa dominada por el parámetro civilizador-modernizador. ${ }^{42}$ Esta concepción reprodujo un férreo determinismo a la hora de identificar el lugar en donde se encontraba la civilización y, en contrapartida, la barbarie, reproduciéndose rasgos estereotipados y exógenos tales como ausencia de condiciones materiales modernas (el uso de maquinarias y tecnologías de cultivo) y rasgos culturales decadentes (ocio, ignorancia, falta de moral, escasez de aseo y ebriedad); ${ }^{43}$ todas ellas fisonomías peyorativas que encontraron un sustento en las observaciones de expedicionarios fiscales chilenos como Alejandro Bertrand y Francisco Vidal Gormaz, ${ }^{44}$ los que construyeron una imagen agreste del desierto tarapaqueño, de su zona andina y sus habitantes. Bertrand, por ejemplo, describirá la parte central del territorio tarapaqueño como una «pampa árida no interrumpida» ${ }^{45} \mathrm{y}$ a la población de los valles pre-cordilleranos como escasa en su condición civilizada en la medida que eran «en general [de] poco espíritu de asociación i progreso» ${ }^{46}$ Vidal Gormaz, por su parte, señalará a la pampa ubicada en la depresión intermedia como «un extenso desierto donde la naturaleza parece dormir el sueño de los siglos», letargo inhospitalario únicamente interrumpido por las manos de los hombres chilenos «hijos de la civilización». ${ }^{47}$ Del mismo modo que Bertrand y Vidal Gormaz, Francisco Javier Ovalle, un periodista de comienzos del siglo XX partidario de la chileniza-

42 La oficialización del propósito civilizador se encuentra en la Circular del Ministro de Relaciones Exteriores, José Manuel Balmaceda, «La misión civilizadora de Chile», Diario Oficial, Santiago de Chile, 25 de julio de 1881.

43 Figueroa, 2010: 8-9.

44 Alejandro Bertrand, geógrafo e ingeniero, en el primer año de la guerra del Pacífico (1879) llevó a cabo en su calidad de funcionario fiscal una serie de estudios exploratorios mandatados por el Gobierno de Chile en las regiones de Antofagasta, Tarapacá, Arica y Tacna que se tradujo en varios informes y mapas. Al poco tiempo de acabar con esta tarea, fue nombrado jefe de la Sección de Cartas y Planos de la Oficina Hidrográfica de Chile. En tanto Vidal Gormaz, marino e hidrógrafo, en 1874 fue nombrado el primer Director de la Oficina Hidrográfica de la Marina Nacional. En este rol, durante el conflicto con Perú y Bolivia tuvo a cargo la realización de distintos estudios sobre la costa peruana de Tarapacá, Arica y Tacna.

45 Bertrand, 1879a, 7 y 9; Bertrand, 1879b, 3-4. Orográficamente esta sección se denomina depresión intermedia y se compone en su lado occidental por la pampa salitrera (una de las fracciones con menos disponibilidad de agua) y por el borde oriental por la pampa del tamarugal. Desde este último punto se accede a los oasis pie-montanos como el de Pica y al espacio andino de pre-cordillera y altiplano.

46 Bertrand, 1879a, 21.

47 Vidal Gormaz, 1879, 6-7. 
ción, ${ }^{48}$ se referirá a la pampa tarapaqueña como un «gran potrero sin fin ni límite» donde no hay vegetación y a los pobladores de la pre-cordillera y el altiplano como «tribus indias [que] viven sumidos en la ignorancia» al no saber «definidamente bajo qué gobierno viven [y creer] casi todos que todavía dependen de la autoridad del Perú». ${ }^{49}$

El carácter pre-juicioso de las descripciones emitidas por los expedicionarios y cronistas chilenos quedará en evidencia a partir de las afirmaciones de Guillermo Billinghurst, probablemente el mayor conocedor de la geografía física y humana de esta región entre mediados del siglo XIX y comienzos del XX..$^{50}$ Basado en su ilustrado acervo afirmará:

Todo el que haya podido formarse una idea más o menos aproximada de la geografía de Tarapacá por la reseña que precede, habrá visto cuan incorrecta e infundada es la general creencia de que esta provincia es un árido desierto de arena, completamente desprovisto del agua que es el primer elemento de vida para las poblaciones. Se ha creído siempre por falta de conocimientos geográficos de este territorio, que Tarapacá no es sino una inmensa sabana de sal y que, por lo tanto, la industria agrícola no tiene razón de ser aquí. ${ }^{51}$

De este modo, en la provincia de Tarapacá la representación de lo civilizado se situó en donde operó y se construyó este discurso-práctica: en el aparato estatal, en los agentes fiscales, en la sociedad regional dominante que residía en los puertos, pueblos y oficinas salitreras (es decir, urbana, blanca y mayoritariamente chilena), en contrapartida de aquellos otros lugares y gentes que eran más bien merodeadores de lo rústico y de la barbarie (los indígenas y los campesinos mestizos). Tal paradigma terminó por consolidarse a partir de la conjunción entre el desmedido interés de Chile

48 Ovalle, periodista, nieto del diputado Francisco Javier Ovalle Bezanilla y bisnieto del presidente José Tomás Ovalle, dedicó su presencia en la provincia de Tarapacá a promover el proceso de chilenización convirtiéndose en la práctica, aunque no lo era formalmente, en un colaborador del aparato fiscal chileno. Su labor periodística y de cronista en Tarapacá fue parte de una estrategia del gobierno chileno de usar civiles en los territorios conquistados del norte para difundir y afianzar sus iniciativas chilenizadoras. Prueba de lo anterior, es que el año 1915 pasa a ser un agente fiscal a plenitud al nombrársele intendente de Valparaíso.

49 Ovalle, 1908, 19 y 173-174.

50 Guillermo Billinghurst nació en Arica el 27 de julio de 1851 y vivió su adolescencia y adultez en Iquique. Se desempeñó como empresario, periodista e intelectual autodidacta interesado en la historia y la geografía tarapaqueña. En 1912 fue elegido presidente del Perú y con anterioridad fue diputado por Iquique, vice-presidente del Perú y alcalde de Lima. En su calidad de intelectual autodidacta publicó importantes obras sobre la agricultura, la geografía, el agua potable, el salitre y los ferrocarriles de Tarapacá. Muere en Iquique el 28 de junio de 1915. Ver González, 2000.

51 Billinghurst, 1888, 93. 
por la riqueza y la renta salitrera y los lineamientos civilizadores y modernizadores, lo que llevó a la administración fiscal chilena a diseñar e implementar con celeridad una política estructurada y funcional que terminó integrando y visibilizando una porción de la geografía tarapaqueña, la pampa y la costa por estar ahí instalada la industria del nitrato, y a su vez desafectando premeditadamente aquellas áreas que no fueron gravitantes, el espacio andino de pre-cordillera y altiplano, para su economía dependiente de la renta salitrera. ${ }^{52}$

Evidentemente en los tipos conceptuales que instalaron los expedicionarios y que reprodujeron los funcionarios estatales hubo tanto un acompañamiento epistemológico del positivismo, especialmente biologicista, como de la idea de progreso, provocando que gran parte de los discursos oficiales chilenos, como señala Carolina Figueroa, terminaran acentuando relaciones binarias (del tipo civilización/barbarie, o modernos/atrasados) para graficar las características tanto del espacio tarapaqueño como de las poblaciones residentes en él. ${ }^{53}$ Será en función de la carencia o no de las instituciones civilizadoras (la escuela, la cárcel, los edificios públicos, el hospital, etc.) que la administración estatal chilena instalada en esta región construirá un paisaje de progreso que situará como núcleo de referencia de la condición civilizadora a las ciudades (Iquique y Pisagua) y el reducto de la barbarie a la zona rural andina y las sociabilidades de los obreros salitreros alteradoras del orden. ${ }^{54}$ Así lo explicitará el intendente Bulnes a mediados de 1884:

Llamo especialmente la atención de VS sobre la circunstancia de que en esa región todos sus habitantes son peruanos, sin mezcla alguna de otra nacionalidad.

En las salitreras y en las poblaciones de la costa, donde existe una activa competencia de trabajo, el elemento chileno y el extranjero, más rigorosos como fuerza y capital, han dominado por decirlo así, bajo su acción a los peruanos y puede por consiguiente mirárseles bajo el mismo punto de vista que a los demás habitantes del territorio nacional. No sucede lo mismo en las quebradas del interior. Allí palpita bajo la influencia de costumbres seculares, una nacionalidad distinta que conserva sus usos y su sistema de vida, su traje, su idioma y su religión, porque aún esta misma se distingue por sus prácticas infantiles, de lo que ella representa en las poblaciones civilizadas de Chile..$^{55}$

52 Castro, 2005. La importancia del área costera (sus puertos) y de la pampa (sus oficinas salitreras) por sobre el espacio andino en el reordenamiento político-administrativo y económico del territorio tarapaqueño durante la administración chilena en el lapso de fines del siglo XIX y comienzos del XX, se verifica también en Ronsenblitt, 2007, 280-282.

53 Figueroa, 2011.

54 El concepto de «paisaje de progreso» está tomado de Figueroa, 2011.

55 ANC, AIT, 67, Iquique, 5 de junio de 1884. 
El territorio tarapaqueño, consecuentemente, operó en el marco de la chilenización bajo el principio de la legitimación del espacio geográfico, pasando el aparato estatal de la utopía al ejercicio efectivo de la soberanía. ${ }^{56}$ Si bien el territorio tarapaqueño, desde la perspectiva de asentar y expandir soberanía, adquirió la capacidad simbólica de unificar sentidos en torno al lugar/espacio habitado (y económicamente ocupado), tal ejercicio - como ya advertimos - no fue homogéneo. Por una parte, la zona andina fue excluida o escasamente emparentada con los parámetros civilizadores y modernizadores de la chilenización. Por otra, la pampa y la costa, donde se encontraba la riqueza salitrera, fue el área privilegiada para asentar la administración estatal y sus dispositivos, lo que Enrique Rajchenberg y Catherine Héau-Lambert denominan el epítome de lo nacional. ${ }^{57}$ En efecto, a diferencia del espacio andino (y los andinos indígenas y mestizos), el área de la costa-pampa pasó a tener en la retórica y en la práctica estatal chilena un densidad simbólica, pasando a desempeñar por lo mismo una metonimia territorial al quedar radicada ahí la representación de lo chileno, con la salvedad de los obreros pampinos al ser, igual que los indígenas, identificados y caracterizados como portadores de la barbarie a razón de sus prácticas inmorales (ebriedad, revoltosos al demandar sus derechos laborales, adscripción a las corrientes anarquistas y socialistas, violentos, etc.). ${ }^{58}$ Desde esta perspectiva, la temprana posición de Gonzalo Bulnes marcó rumbo en lo tocante a los lineamientos estratégicos en orden a la organización política del territorio tarapaqueño ahora en manos chilenas:

La primera cuestión que surge cuando se trata de la organización de este territorio es saber si conviene crear para aquellos lugares una sección administrativa especial. Debo dar a VS. las razones que me inclinan a contestar en sentido negativo a la pregunta anterior. Un gobernador tropezaría en el servicio administrativo con las siguientes dificultades:

$1^{\circ}$ La distancia que divide las quebradas entre sí, de tal modo que siempre sería más difícil la comunicación entre una quebrada cualquiera y la capital del departamento, que entre aquella y la costa. [...] $2^{\circ}$ Las quebradas del interior se encuentran en un estado de suma pobreza sin que pueda suponerse que su situación se modifique

56 Siguiendo la postura analítica de Mónica Quijada (2002, 111-112), la disputa por la soberanía desatada en las provincia de Tarapacá y Arica entre las décadas de 1880 y 1920 demarca el perfil de una región de frontera exterior (que se incorpora), a diferencia del caso del sur argentino ocurrido en el mismo período donde no fue la disputa por la soberanía el eje del conflicto sino la tenencia del espacio a partir de su condición de frontera interior.

57 Rajchenberg y Héau-Lambert, 2007, 42.

58 Esta tipología barbarizada del obrero salitrero se aborda en: Figueroa y Silva, 2013, 202-205. 


\section{LUIS CASTRO CASTRO}

o mejore. [...] Esta gran pobreza enervaría o haría imposible toda acción administrativa. $3^{\circ}$ El peligro que bajo el punto de vista de la asimilación de la raza peruana podría traer la adaptación de un régimen administrativo severo y nuevo que viniera a trastornar sus prácticas. ${ }^{59}$

Para Bulnes, estas dificultades estructurales ameritaban una administración fiscal orientada estratégicamente hacia las zonas bajas, por tanto propuso una división en dos departamentos: el de Iquique y el de Pisagua, ordenamiento que lo justificó arguyendo razones tales como:

hoy la región salitrera ha relegado a una escala subalterna la importancia del interior, y de aquí proviene que sus intereses administrativos deben estar subordinados a los de la costa. [...]

[...] en pocos años más será preciso crear el departamento de Patillos, ${ }^{60} \mathrm{y}$ entonces cada una de las divisiones administrativas tendrá entre sus dependencias una o dos de las quebradas más importantes del interior. Y si la raza peruana que está obligada por sus negocios a vivir en contacto con la región de la costa, se incorporaría mejor en las prácticas de nuestro sistema de gobierno y de nuestro adelanto social. ${ }^{61}$

Si duda que este tipo de planteamiento modernizador apuntó a establecer una vinculación subordinada en lo político-administrativo de la población peruana, boliviana e indígena rural de la región, un aspecto que fue concordante con la misión civilizadora que se había impuesto Chile para con estos territorios anexados. Por lo mismo, el imaginario territorial tarapaqueño construido por los agentes estatales chilenos terminó, por un lado, delimitando a razón de los intereses económicos la diferencia binaria entre civilización y barbarie como, por otro, configurando el entretejido del proyecto de dominación/subordinación contenido en la médula de la chilenización. De este modo, el espacio andino y quienes residían en él pasaron a ser el otro de la civilización.

Congruentemente, el espacio estatal construido - que en definitiva era lo chileno por sobre lo peruano y lo boliviano- pasó a ser una utopía cimentada a partir de clasificaciones objetivadas (linderos, toponimia, registro legal de propiedades, etc.) que terminaron, por una parte, plasmando una gama restringida de posibilidades de representación como, por otra, avalando categorías más bien ambiguas y contradictorias. ${ }^{62}$ Así, los rasgos

59 ANC, AIT, 67, Iquique, 5 de junio de 1884.

60 Asentamiento costero al sur de Iquique que tuvo una relativa connotación entre las décadas de 1880 y 1920 como yacimiento guanero, destacándose adicionalmente como un puerto natural de excepción.

61 ANC, AIT, 67, Iquique, 5 de junio de 1884. 
y características asumidos y socializados por los agentes de la administración estatal chilena sobre el espacio tarapaqueño pasaron a ser parte de los parámetros del «deber ser» en tanto una pauta cultural impositiva y ordenadora que movilizó instrumentos, saberes y dispositivos estandarizados. Sin embargo, en la práctica esta utopía tuvo que lidiar con las heterotopías de los sujetos, los que en su cotidianidad (a partir de intereses colectivos e individuales) minaron e inquietaron la quimera chilenizadora de la homogeneidad. ${ }^{63}$ En efecto, las prácticas de los sujetos al amparo de su pluralidad -indios y mestizos, peruanos y bolivianos, nacionales y extranjeros, etc. ${ }^{64}$ reprodujeron distintos niveles de resistencia y negociación que terminaron por minar la sintaxis chilenizadora, ${ }^{65}$ es decir, todo aquello que posibilitaba construir los discursos y las narrativas a partir de mantener juntas las palabras y las cosas. ${ }^{66}$

De este modo, el propósito de nacionalizar la frontera (el territorio incorporado a la soberanía disputada) chocó frecuentemente con pertenencias endebles, difusas, condicionadas, intencionadas, dislocadas y ambiguas de sus residentes, operando por el contrario dinámicas flexibles que posibilitaron, muchas veces con dificultades y otras tantas con cierta facilidad, la coexistencia de los modos de vida, de producción y de interacción con la institucionalidad de la autoridad chilenizadora ${ }^{67}$ Así, Chile incorpora la provincia de Tarapacá a razón principal de sus intereses económicos (el salitre) condicionando funcional y asimétricamente los componentes culturales, un acto equivalente y semejante con lo ocurrido en otros espacios fronterizos sujetos a dominación - tal como lo grafican Graciela Sarti y

62 Esta idea del territorio conformado a partir de parámetros objetivos a efecto de posibilitar e imponer las prácticas sociales congruentes con el proyecto político del constructor estatal ha sido tomada de Muñoz Arbelaez, 2007.

63 Respecto a estas resistencias a la chilenización que delatan heterogeneidad consultar Castro y Rivera, 2011; Figueroa, 2011; Aguilera, 2003, 21-36; Aguilera, 2008; Díaz, Ruz y Mondaca, 2006, 215-235.

64 Esta pluralidad fue en muchas ocasiones además superpuesta y móvil. Por ejemplo, un residente campesino de los valles andinos podía ser indígena y a la vez peruano y boliviano, al mismo tiempo al portar (o adscribírsele) la nacionalidad peruana o boliviana pasaba a ser extranjero, o si predominaba la condición étnica podía ser considerado como nacional, bárbaro pero de este lado del territorio. Aún más, no teniendo apellidos indígena explícitos y ocupando roles relevantes en su comunidad (como miembro de ella o como funcionario fiscal) podía ser tipificado como mestizo, condición más cercana a los parámetros civilizadores que la de indio. Todo esto por separado o entremezclado al amparo de las perspectivas o los intereses tanto de la contraparte como de los propios sujetos tipificados.

65 Sobre este punto consultar Castro, 2011, 271-300; Castro, 2013a, 361-385.

66 Foucault, 2005.

67 Una descripción semejante para el espacio fronterizo chaqueño argentino, boliviano y paraguayo en Figallo, 2003. 
Mariano Rodríguez para el caso argentino- ${ }^{68}$ en directa correspondencia a la conformación y expansión de los estados nacionales, dinámica que traerá consigo una confrontación con la otredad (los bárbaros) a partir de la disputa de los recursos productivos contenidos en los lugares conquistados. ${ }^{69}$

El arraigo de los propósitos civilizadores y su vinculación con el proceso de construcción nacional, de este modo, se situó en el territorio tarapaqueño como el elemento integrador-subordinador de la heterogeneidad social y cultural de sus residentes al radicar en él (en tanto un lugar chileno) la unidad y pertenencia a razón de un soporte jurídico-administrativo. ${ }^{70}$ Según Carmen Mc Evoy, los agentes estatales chilenos lograron organizar una estructura burocrática exitosa en los territorios ocupados y anexados a partir de la guerra del Pacífico, lo que fue un aporte a la construcción estatal de Chile al amparo de una modalidad atípica al desarrollarse este proceso más allá de sus fronteras, delatando un rol transnacional en su dinámica expansiva. ${ }^{71}$ La virtud, según esta autora, es que el estado chileno supo desdoblarse perfeccionando sus saberes administrativos al amparo de un poder transnacional que lo terminó fortaleciendo. ${ }^{72}$

\section{La representación del indígena y el mestizo andino: una tipología de la barbarie}

Así como en otros lugares de América Latina la imagen del otro durante el siglo XIX supuso una actitud sobre una realidad natural extraña que debía ser integrada a un discurso histórico y antropológico formulado con anterioridad, ${ }^{73}$ en Tarapacá ocurrió lo mismo pero con un ingrediente adicional: el no ser una frontera interna como en los casos del desierto patagónico argentino y el oriente ecuatoriano,${ }^{74}$ sino una frontera externa

68 Sarti y Rodríguez, 1992, 215.

69 Este tema se aborda en Castro, 2014, 231-251; Castro, 2013b, 146-157.

70 Quijada, 2000, 382.

71 Cabe recordar en este sentido que la provincia de Tarapacá pasó a ser parte de la soberanía chilena en octubre de 1883 al firmarse el tratado de paz con el Perú, y a su vez la zona de Arica se incorpora definitivamente al territorio nacional a partir de lo acordado en el famoso y controversial tratado de 1929 entre Chile y Perú para poner un término definitivo a las consecuencias de la guerra del Pacifico. Esto significa que durante un tiempo no menor Chile actuó al amparo de acción administrativa como si tuviera plena potestad y soberanía en territorios anexados (Tarapacá) y cautivos (AricaTacna), es decir, técnicamente fuera de sus fronteras.

72 Mc Evoy, 2006, 215-216.

73 Reyero, 2004, 722. 
preliminarmente re-significada por otra nación. Por tanto, la construcción del imaginario nacional chileno no operó en un vacío, por el contrario debió sostenerse y lidiar al mismo tiempo con una comunidad imaginada, no obstante débil y fragmentada, anterior. ${ }^{75}$ En efecto, no sólo eran indios y campesinos mestizos los portadores de la barbarie a chilenizar, sino a la vez peruanos o bolivianos, superponiendo identidades que, por más difusas que se desplegaran, estaban muy arraigadas en ciertas prácticas e intereses. Del algún modo la tipificación exógena y prediseñada de la agencia estatal chilena, a razón de este escenario, se vio obligada a situarse entre una retórica dura (para tranquilidad de la utopía civilizadora y modernizadora) y una práctica administrativa conciliadora y blanda (para bien de los intereses fácticos en juego). ${ }^{76}$ Lo anterior se tradujo en que, desde la década de 1880, en el espacio andino tarapaqueño no sólo se hizo evidente el despliegue de los dispositivos estatales tendientes al control administrativo, entre ellos los modos de identificación socioculturales, sino también las conductas adaptativas de la población local orientadas a resguardar sus intereses. Para José Luis Martínez este rasgo fue una «manifestación más de una vieja tradición cultural» puesta en práctica para manejar de modo flexible diversas situaciones y actitudes «orientadas siempre, desde la óptica indígena, a optimizar su posición respecto al estado o la sociedad dominante». ${ }^{77}$ Como nos lo indican José Valcuende y Laís Cardia las «poblaciones fronterizas aprenden a instrumentalizar la frontera en función de intereses concretos, a partir de los cuales se activa la idea de comunidad nacional o de comunidad interfronteriza». ${ }^{78}$ Consecuentemente, las imágenes chilenizadoras del indio y de los campesinos mestizos andinos se desplegarán demarcando no sólo conductas sino también modalidades administrativas.

En consideración de lo anterior, la tipología chilenizadora de la alteridad conjugó la funcionalidad con el paradigma. Por lo mismo, en Tarapacá durante el transcurso de las décadas de 1880 a 1920 no hubo una categorización fiscal específica y única sobre los aymaras y la población campesina andina, sino más de una connotación en la medida que el parámetro se acercaba a lo político (la ciudadanía) o se aproximaba a la moral (las prácticas y costumbres); por ejemplo, a los habitantes vallesteros (tie-

74 La dimensión frontera interior en estos casos verlas en Quijada, 2002 y Esvertit Cobes, 2001.

75 La comunidad imaginada la situamos tanto en la tesis de Anderson, 1993, como en los planteamientos de Chatterjee, 2007.

76 Ver: Castro y Rivera, 2011, 271-300; Castro, 2013, 146-157.

77 Martínez, 1994, 201.

78 Valcuende y Cardia, 2009, sin páginas. 
rras bajas) normalmente se les denominará como peruanos o campesinos, en cambio a los residentes altiplánicos (tierras altas) se les motejará como indígenas o indiada ${ }^{79}$ no siendo esta delimitación estricta ni rígida ya que bastaba con el desplazamiento (algo común e intenso entre las poblaciones andinas) para lograr de parte de la burocracia un cambio en el modo de identificación. ${ }^{80}$ Tal recurso, finalmente, le permitió al aparato estatal chileno minimizar y relativizar el impacto y la reproducción de la comunidad imaginada anterior al dislocar a los sujetos entre identidades imposibilitadas de desplegarse a plenitud. Con ello, queremos señalar que estas poblaciones en más de una ocasión, a pesar de tener cierta fidelidad hacia un sentimiento pro-peruano o pro-boliviano, sin tener cabal conciencia de la pertenencia a una nación, terminaron optando por sus identificaciones localistas (en referencia al poblado o localidad donde residían) ya que ellas les posibilitaban acceder y/o negociar a (con) los dispositivos chilenizadores y resguardar convenientemente sus intereses económicos, políticos e, inclusive, étnicos ${ }^{81}$ más aún cuando la plataforma de las representaciones posibilitaba flexibilidad y movilidad no siempre controlable por la burocracia. ${ }^{82}$ A la larga, esta última tendencia facilitó la adscripción de los lugareños

79 ANC, AIT, 197, Tarapacá, 20 de mayo de 1895; Archivo Regional de Iquique, Fondo Intendencia de Tarapacá (AITRI), 7, Subdelegados 1910, Tarapacá, 8 de agosto de 1910, 18 de octubre de 1910 y 6 de noviembre de 1910; AITRI, 28, Subdelegaciones 1921, Tarapacá, 28 de septiembre de 1920.

80 Esta movilidad de tierras bajas hacia tierras altas y viceversa por parte de las poblaciones andinas, data desde el período Formativo (2500 a.C.) con el propósito de acceder a distintos pisos ecológicos y con ello diversificar la obtención de recursos. A partir de la segunda mitad del siglo XIX, especialmente bajo administración chilena, esta movilidad se restringió entre el altiplano y los valles a raíz de la ocupación de la pampa y la costa por poblaciones allegadas desde otros lugares, algunos muy lejanos, para aventurarse en la industria minera del salitre. Al amparo de esta dinámica, no fue raro que residentes de los pueblos cabeceras de los valles (como Tarapacá, Camiña o Mamiña) tuvieran propiedades en el altiplano, o bien que ganaderos altiplánicos vivieran algunos meses del año en los valles en habitaciones propias o arrendadas. De este modo, complementaban la actividad agrícola con la ganadera, o bien se desplazaban estacionalmente para realizar actividades comerciales acreditando residencia en los valles como el altiplano, además de otros mecanismos que tuvieron que ver con dinámicas étnicas en torno a la concepción dual del espacio. De ahí que fue recurrente que muchos de estos residentes rurales serán doblemente tipificados por los funcionarios fiscales chilenos (como peruanos cuando residían en las localidades vallesteras o como indios cuando habitaban en los poblados altiplánicos), aún más cuando muchos de ellos no entendían las modalidades andinas de movilidad y ocupación del espacio.

81 Este tema está tratado en Castro y Rivera, 2011.

82 La demostración más clara de esta situación es la ocupación de roles administrativos en el aparato estatal chileno (inspectores y jueces de distritos principalmente) por parte de residentes vallesteros y altiplánicos, generando un quiebre estructural en la tipología civilizadora. También en el caso de aquellos individuos que tenían pastales y animales en las tierras altas y chacras en las tierras intermedias y bajas, lo que los hacía aparecer indistintamente como indios o como campesinos o ciudadanos peruanos o bolivianos en las referencias administrativas, distinciones que por lo general ellos mismos tensionaban para mantener e incluso acrecentar sus granjerías económicas. 
andinos - especialmente del altiplano en consideración de sus diferencias con los campesinos del lado boliviano- a lo chileno sin mayor carga impositiva fáctica, aunque sí simbólica. ${ }^{83}$

El uso de categorías como peruanos, bolivianos, indios, indiada, indígenas, naturales, lugareños, agricultores y campesinos, de esta manera no sólo fue recurrente, superpuesta y dinámica, sino también jerárquica, ordenadora y referencial. Después de todo, la supremacía civilizadora la portaba el conquistador/dominador por más que el sujeto subalterno la permeara recurrentemente $-\mathrm{y}$ los agentes fiscales de menor rango tambiéna la hora de visibilizar la posibilidad de un beneficio pecuniario. Por ello, a la par de las denominaciones, operó una visión más o menos genérica de estar frente a poblaciones atrasadas, pobres y poco civilizadas, un aspecto que con una descarada franqueza resaltará a inicios de 1881 el periódico El Veintiuno de Mayo al justificar y validar el asentamiento administrativo de Chile en tierras tarapaqueñas al hecho de estar ante una «diferencia de razas» al ser la peruana e indígena «heterogénea, ignorante, perezosa y cobarde» y la chilena «homogénea, inteligente, trabajadora y valerosa» ${ }^{84}$ como, por otra, el subdelegado de Pica Valdés Carrera cuando, en su memoria anual dirigida al jefe político de Tarapacá a fines del año 1883, comente que para poder civilizar y chilenizar a los «semisalvajes» habitantes andinos había que darles una «organización política distinta» por ser «tan indígenas» y encontrarse en estado «primitivo con todos los vicios imaginables» ya que son «sucios, flojos e indolentes y nada hacen por mejorar su condición si la autoridad misma no los impele a la fuerza» ${ }^{85}$ Percepción que a mediados de 1884 también delatará el intendente Gonzalo Bulnes al afirmar, en un informe remitido al ministro del interior, que en los valles y en el altiplano «vive amontonada una población indígena importante como número, si bien desprovista de actividad y de energía moral». ${ }^{86}$

Las percepciones del editor de El Veintiuno de Mayo, un periódico pro chilenizador, de Valdés Carrera y de Bulnes no hicieron más que evidenciar la condición de agentes tributarios de las construcciones culturales elaboradas por quienes habían explorado estos territorios antes de la guerra del Pacífico con fines estratégicos adscritos a los intereses chilenos sobre la

83 Castro, 2012, 237-334.

84 El Veintiuno de Mayo, Iquique, 23 de enero de 1881.

85 ANC, AIT, 43, Pica, diciembre 1883, 64.

86 ANC, AIT, 67, Iquique, 5 de junio de 1884. 
riqueza salitrera ${ }^{87}$ entre ellos Alejandro Bertrand quién no dudará en afirmar que la «población civilizada» de Tarapacá era «poco numerosa [y] en general [tenía] poco espíritu de asociación y progreso», siendo:

casi toda indígena y de carácter bajo y humilde hasta la degradación [al vivir] en la más completa ociosidad, entregados a la bebida y a la concupiscencia, lo que los hace de un tipo bastante repugnante. ${ }^{88}$

Tales epítetos sustentarán en Bertrand un parámetro sociocultural que le permitirá asociar lo indígena con la condición de bestialidad:

Las indias de esta localidad, como las de Bolivia, llevan siempre sus hijos cargados a la espalda y gran cantidad de coca dentro de la boca; el continuo movimiento de las mandíbulas les ensancha los músculos de las mejillas y les gasta las muelas como a los rumiantes. ${ }^{89}$

A partir del condicionamiento ideológico articulado y reproducido en los comentarios categoriales de los exploradores fiscales chilenos en comisión de servicio, el uso de este tipo de adjetivos no fue privilegio de los primeros funcionarios chilenos de Tarapacá, sino también de una sesgada percepción que se reiterará en los numerosos burócratas a cargo de las reparticiones rurales entre las décadas de 1880 a $1930 .{ }^{90} \mathrm{~A}$ inicios del mes de junio de 1884, por ejemplo, el jefe político en su memoria administrativa correspondiente al año 1883 señalaba al ministro del interior que la presencia de agentes fiscales y curas chilenos en la zona andina estaba destinado a «vencer las resistencias de la raza» y «realizar una completa transformación en los hábitos y sentimientos del pueblo indígena». ${ }^{91}$ En 1888, por su parte, el juez de la subdelegación de Tarapacá caracterizará a

87 Por ejemplo Vidal Gormaz 1879, 3, declarará que el propósito central de su trabajo era el de ser una «guía segura y fácil de consultar para el ejército de ocupación del Desierto, desde el oficial de Estado-Mayor, hasta el cabo y el soldado extraviado en aquellas vastas soledades».

88 Bertrand, 1879a, 21-22.

89 Bertrand, 1879a, 21.

90 Tal fenómeno de diseminación es posible encontrarlo igualmente en otras regiones de Sudamérica, particularmente en Argentina donde primarán categorías para describir y caracterizar a los indígenas tales como: atónitos, pasivos, exóticos, deshumanizados, ociosos, abominables, holgazanes, lascivos, feos, ebrios, inútiles, impíos, incapaces, etc.; es decir, la reproducción de un conjunto amplio de baterías socioculturales. A este respecto revisar Navarro Floria, 2001, 348-349; Penhos, 1992, 189 191; Sarti y Rodríguez, 1992, 216-218; Reyero, 2004, 724-726.

91 ANC, Fondo Ministerio del Interior, 100, Iquique, 3 de junio de 1884. El Jefe Político de Tarapacá hasta inicios de junio de 1884 fue Francisco Valdés Vergara, el último en cumplir este cargo ya que a mediados de este mes, preparando lo que sería la creación de la provincia de Tarapacá en octubre de ese mismo año, se creará el puesto de intendente que lo ocupará Gonzalo Bulnes. 
los residentes del pueblo altiplánico de Cultani, que según sus antecedentes estaban armados para resistir un procedimiento a su cargo, como «indios semisalvajes». ${ }^{92}$ Del mismo modo en 1908 Francisco Javier Ovalle, a través de su estudio sobre Iquique, dirá que las bolivianas que recorrían las calles de este puerto, donde lo boliviano será equivalente a lo indígena, «exhiben un rostro pálido, mofletudo y melancólico» y en sus espaldas «duerme una criatura, fruto de su vientre y de sus desabridos amores». ${ }^{93}$ En 1912, en tanto, el gobernador del departamento de Pisagua, Luis Lazo, le dirá al intendente de Tarapacá, a propósito de las instrucciones dadas al subdelegado de Camiña por orden del ministerio de hacienda relativas a una alza en los cánones de arriendo que se debían cobrar y el reclamo de los residentes de esta jurisdicción por esta medida, que la molestia presentada por los agricultores no tenía otro origen que su condición casi en su totalidad de «indígenas peruanos» y de «timoratos o ignorantes». ${ }^{94}$ En 1919, por su parte, el juez de la subdelegación de Tarapacá, en el marco de una evaluación de su gestión enviada al intendente para su conocimiento, llamará la atención de que casi la totalidad de los habitantes de su jurisdicción eran de mismo no debía escapar a la consideración de las máximas autoridades provinciales de la «ruda labor» que él debía llevar a cabo para implantar las «leyes i costumbres del país». ${ }^{95}$

Las referencias genéricas, jerárquicas y degradadoras sobre la población andina, sin embargo, no serán exclusivas, deberán convivir con denominaciones más funcionales que tendrán por propósito sustantivar todo aquello situado al otro extremo de lo chileno para, de esta manera, posibilitar el asentamiento de una dominación más allá de los sujetos. Para Pedro Navarro Floria tal intencionalidad, considerando su estudio sobre el sur argentino, emergió a partir de que los indios para los aparatos estatales en expansión dejaron rápidamente de ser fenómenos de observación y pasaron a constituirse en objetos políticos. ${ }^{96}$ En el caso de Tarapacá este aspecto no fue menor si consideramos que, no obstante en el tratado de 1883 el Perú cede a perpetuidad la soberanía de esta provincia a Chile, los residentes de la zona andina en estricto mantuvieron por largo rato la potestad de optar por las reivindicaciones nacionales peruanas en tanto potenciales electores

\footnotetext{
92 ANC, AIT, 172, Tarapacá, 24 de diciembre de 1888.

93 Ovalle, 1908, 18.

94 AITRI, 23, Gobernación de Pisagua 1912, Pisagua, 2 de enero de 1912.

95 AITRI, 11, Subdelegaciones 1919, Tarapacá, 16 de agosto de 1919.

96 Navarro Floria, 2001, 349.
} 
del plebiscito que debía zanjar la cuestión Arica-Tacna. Es decir, cabía la posibilidad de que todos ellos fijaran residencia en Arica o Tacna y votaran a favor del Perú inclinando la balanza en dirección opuesta a los intereses chilenos.

Desde esta mirada, la acción denominativa aparte de reflejar cierto desconocimiento, prejuicio y desconcierto de/sobre la realidad sociocultural tarapaqueña por parte de los agentes fiscales chilenos, tuvo por intención contener funcionalmente la alteridad andina en los marcos del quehacer administrativo estatal mediante espacios de negociación, participación y acceso a las utilidades, una composición nada de extraña, ni menos contradictoria, si se toma en cuenta que la tipología de la barbarie no sólo se nutrió de la variante antropológica (las comunidades más alejadas del paradigma evolucionista de civilización/barbarie), sino también de la sociológica y la política al poner atención en los grupos refractarios al nuevo orden en construcción y en los sistemas de vida que estaban afuera de lo deseado. ${ }^{97}$

Consecuentemente, más allá de la carga peyorativa de las denominaciones socioculturales sobre la población andina de Tarapacá, existieron matices que reflejaron posturas más coincidentes con los requerimientos prácticos y funcionales en orden a conjugar, por una parte, las valoraciones sobre y hacia los indígenas - como de los no chilenos también-y, por otra, el modelo de sociedad que se deseaba construir en este territorio incorporado. La postura proteccionista del propio intendente Gonzalo Bulnes en 1884 y del director general de obras públicas en 1918 respecto a los recursos productivos ${ }^{98}$ como el agua de la pre-cordillera y el altiplano, apetecidos para viabilizar proyectos modernizadores a gran escala, ${ }^{99}$ será un claro reflejo de las traducciones contextualizadas al amparo de la experiencia y los intereses adquiridos por parte de los burócratas chilenos asentados en Tarapacá. Por lo demás, en estos comportamientos no hubo discordancia, sino que un estricto apego a un criterio político muy refinado que buscó afianzar dos objetivos: no incurrir en conflictos innecesarios con una población no chilenizada a plenitud, como la andina indígena y mestiza, y dejar establecido que se estaba ante una administración sometida al imperio de la ley y no a determinaciones irracionales.

97 Las variantes tipológicas de la barbarie se abordan en Navarro Floria, 2001, 345-347.

98 ANC, AIT, 68, Iquique, junio 1884, sin foliación; ANC, Fondo Ministerio de Industria y Obras Públicas, 2119, Santiago, 28 de diciembre de 1918.

99 Ver Castro, 2004, 2005 y 2010. 


\section{Conclusiones}

La construcción de un territorio nacional y una nación durante las primeras décadas de administración chilena de Tarapacá, no sólo tuvo que ver con la representación de la utopía modernizadora y civilizadora, sino igualmente con los múltiples dispositivos supeditados a lo económico producto de la importancia de la renta salitrera. Tal articulación, por su condición obligatoria, posibilitó cierta movilidad de los imaginarios sobre la población y el espacio andino toda vez que en estricto, y sobre la formalidad del discurso, lo que realmente le interesaba al aparato estatal chileno era el nitrato y lo que posibilitaba su explotación. La invención de lo chileno, entonces, no se condensó a cabalidad en el área rural pre-cordillerana y altiplánica.

La evidencia de tal escenario estará en la convivencia, no siempre fácil, de las tipologías peyorativas con las conceptualizaciones paternalistas de la otredad, una interacción forzada tanto por los propios funcionarios fiscales chilenos como por los sujetos andinos a razón de conveniencias funcionales. En efecto, el mismo indígena flojo, sucio, indolente y carente de energía moral, podía pasar a ser un mestizo con ciertas virtudes (bajo la lógica de la integración-subordinación como soportadora de la asimetría estructural) en la medida que bajaba desde el territorio agreste e inhospitalario a la pampa a satisfacer los requerimientos de insumos o de mano de obra de las faenas salitreras. De este modo pasaba a ser en la retórica de la representación estatal menos indio, menos sucio, menos flojo, menos indolente, en resumen, menos refractario al ideal chileno del deber ser, condición que duraba hasta que subía nuevamente a las serranías andinas. De ahí que si bien la clasificación del espacio y los sujetos andinos reforzará la visión de los agentes fiscales chilenos demarcado por las oposiciones civilización/barbarie y modernos/atrasados, lo complejo de la heterogénea y dinámica trama sociocultural andina hará de ellos más bien binarismos diluidos.

En estos términos y no obstante que la utopía chilenizadora en lo formal logrará imponer un orden y una jerarquía que condenará al espacio y la población andina a una supeditación estructural, tal construcción será regularmente permeada por las heterotopías contenidas tanto en las traducciones de los funcionarios fiscales chilenos de menor rango asentados en la ruralidad andina como la de los indígenas y mestizos a razón de la imposibilidad, a propósito de la representación de la comunidad imaginada, de 


\section{LUIS CASTRO CASTRO}

operar en un espacio vacío. En efecto, lo nacional chileno en el mundo andino tarapaqueño tuvo que lidiar con contenidos pre-existentes obligando a los imaginarios chilenizadores a dialogar con la heterogeneidad.

Recibido el 29 de mayo de 2013 Aceptado el 22 de septiembre de 2014

\section{Bibliografía}

Aguilera, René: «La anexión del territorio de Tarapacá a Chile y sus efectos en la realidad andina de los valles tarapaqueños (1880 a 1922)», en Gálvez, Macarena; Ruz, Rodrigo y Díaz, Alberto (comps.), Tarapacá un desierto de historias. Historia, cultura y memoria en el norte Chileno S. XIX y XX, Iquique, FONDART y Taller de Investigaciones Culturales (TINCU), 2003, 21-36.

Aguilera, René: Resistencia y ciudadanía en la desperuanización y chilenización de los valles tarapaqueños (1900-1930), Tesis de Magíster en Antropología, Universidad Católica del Norte, 2008.

Anderson, Benedict: Comunidades imaginadas. Reflexiones sobre el origen y la difusión del nacionalismo, México DF, Fondo de Cultura Económica, 1993.

Bandieri, Susana: «Cuando crear una identidad nacional en los territorios patagónicos fue prioritario», Revista Pilquen, XI-11, Viedma, Río Negro, 2009, 1-5.

Bertrand, Alejandro: Noticias del Departamento Litoral de Tarapacá y sus recursos, Santiago de Chile, Imprenta Nacional, 1879a.

Bertrand, Alejandro: Departamento de Tarapacá. Aspecto general del terreno, su clima y sus producciones, Santiago de Chile, Imprenta de la República, $1879 b$.

Billinghurst, Guillermo: Estudio sobre la geografía de Tarapacá, Santiago de Chile, Imprenta de El Progreso, 1888.

Brenna B., Jorge: «La mitología fronteriza: Turner y la modernidad», Estudios Fronterizos, 12-24, Mexicali, 2011, 9-34.

Castro Castro, Luis: «Recursos hídricos altoandinos, estrategias de desarrollo económicos y proyectos de riego: Tarapacá 1880-1930», Chungara, 36-1, Arica, 2004, 205-220.

Castro Castro, Luis: Regionalismo y Desarrollo Regional: debate público, proyectos económicos y actores locales (Tarapacá 1880-1930), Viña del Mar, CEIP Ediciones/Universidad de Valparaíso/Universidad Santo Tomás, 2005.

Castro Castro, Luis: «El estado chileno, los agentes fiscales y el temprano ordenamiento administrativo del espacio andino de la provincia de Tarapacá (18801930)», Chungara, 40-2, Arica, 2008, 219-233. 
Castro Castro, Luis: Estado chileno y poblaciones indígenas: articulaciones y conflictos en el período del rentismo salitrero y la chilenización (Tarapacá 18801930), Tesis de Doctorado en Historia, Universidad de Chile, 2012.

Castro Castro, Luis: Modernización y conflicto social: la expropiación de las aguas de regadío a los campesinos del Valle de Quisma (Oasis de Pica) y el abastecimiento fiscal a Iquique, 1880-1937, Valparaíso, Universidad de Valparaíso Editorial, 2010.

Castro Castro, Luis: «El espacio andino y la administración estatal durante el ciclo salitrero. Tarapacá, 1882-1933», en González, Sergio (comp.), La sociedad del salitre. Protagonistas, migraciones, cultura urbana y espacios públicos, Santiago de Chile, Universidad Arturo Prat/Universidad de Valparaíso/Universidad Católica del Norte y RIL Ed., 2013a, 361-385.

Castro Castro, Luis: «Chilenización, tributos y arriendo de tierras en el espacio andino de Tarapacá (norte de Chile, 1883-1932)», História UNISINOS, 17 2, São Leopoldo, 2013b, 146-157.

Castro Castro, Luis: «La conformación de la frontera chileno-boliviana y los campesinos aymaras durante la chilenización (Tarapacá, 1895-1929)», Historia Crítica, 52, Bogotá, 2014, 231-251.

Castro Castro, Luis y Rivera C., Natalia: «La sociedad rural del oasis de Pica frente al proceso chilenizador: conflictos, interacciones y reacomodos (Tarapacá, norte de Chile 1880-1900)», Estudos Ibero-Americanos, 37-2, Porto Alegre, 2011, 271-300.

Chatterjee, Partha: La nación en tiempo heterogéneo y otros estudios subalternos, Lima, Sephis/CLACSO/IEP, 2007.

Cid, Gabriel: La guerra contra la Confederación. Imaginario nacionalista y memoria colectiva en el siglo XIX chileno, Santiago de Chile, Ediciones Universidad Diego Portales, 2011.

Comisión Central del Censo: Memoria presentada al Supremo Gobierno por la Comisión Central del Censo de 1907, Valparaíso, Imprenta Universo, 1908

Concha, Fabiola y Morales, Paz: «Orden Público» en los primeros años de administración chilena en la provincia de Tarapacá (décadas 1880-1900), Tesis para optar al Título de Profesor de Historia y Ciencias Sociales y al Grado de Licenciado en Historia, Universidad de Valparaíso, 2013.

Díaz Araya, Alberto: «Aymaras, peruanos y chilenos en los Andes ariqueños: resistencia y conflicto frente a la chilenización del norte de Chile», AIBR Revista de Antropología Iberoamericana, 2-1, Madrid, 2006, 296-310.

Díaz Araya, Alberto; Ruz Zagal, Rodrigo y Mondaca Rojas, Carlos: «La administración chilena entre los aymaras: resistencia y conflicto en los Andes de Arica (1901-1926)», Revista Antropológica, 22, Lima, 2006, 215-235.

Dirección General de Estadísticas: Censo de población de la República de Chile levantado el 15 de diciembre de 1920, Santiago de Chile, Litografía Universo, 1925. 


\section{LUIS CASTRO CASTRO}

Esvertit Cobes, Natalia: «Los imaginarios tradicionales sobre el oriente ecuatoriano», Revista de Indias, LXI-223, Madrid, 2001, 541-571.

Figallo, Beatriz: «Espacios nacionales y espacios regionales. Conflictos y concertaciones en las fronteras chaqueñas de Argentina, Bolivia y Paraguay», Anuario de Estudios Americanos, LX-1, Sevilla, 2003, 183-212.

Figueroa Cerna, Carolina: «La genética como discurso político: la escuela primaria rural y la transformación del indígena (Tarapacá 1880-1920)», Naveg@mérica. Revista Electrónica de la Asociación Española de Americanistas, 4, Murcia, 2010. <http://revistas.um.es/navegamerica>.

Figueroa Cerna, Carolina: «Cartografiando El progreso: espacios de civilización y barbarie en la provincia de Tarapacá, norte de Chile (1825-1884)», Scripta Nova. Revista Electrónica de Geografía y Ciencias Sociales, XV-370, Barcelona, 2011. <http://www.ub.edu/geocrit/sn/sn-370.htm> [Consulta: 21 de marzo de 2012].

Figueroa Cerna, Carolina y Silva Torrealba, Benjamín: «Los peligros del furor revolucionario: discursos desde la Iglesia Católica sobre la acción de la mujer en la formación de la moral (provincia de Tarapacá, norte de Chile, 18801910)», Intersecciones de Antropología, 14-1, Olavarría, 2013, 199-2011.

Foucault, Michel: Las palabras y las cosas. Hacia una arqueología de las ciencias humanas, México, Siglo Veintiuno Editores, 2005.

Giordano, Mariana: «Nación e identidad en los imaginarios visuales de la Argentina. Siglos XIX y XX», ARBOR Ciencia, Pensamiento y Cultura, CLXXXV-740, Madrid, 2009, 1283-1298.

González Miranda, Sergio: «Guillermo Billinghurst Angulo: una biografía regional», Revista de Ciencias Sociales, 10, Iquique, 2000, 4-22.

González Miranda, Sergio: Chilenizando a Tunupa. La escuela pública en el Tarapacá andino 1880-1990, Santiago de Chile, Dibam y Universidad Arturo Prat, 2002.

Jiménez Núñez, Alfredo: «La historia como fabricación del pasado: La frontera del Oeste o American West», Anuario de Estudios Americanos, LVIII-2, Sevilla, 2001, 737-755.

Lois, Carla M.: «La invención del desierto chaqueño. Una aproximación a las formas de apropiación simbólica de los territorios del Chaco en los tiempos de formación y consolidación del estado-nación argentino», Scripta Nova. Revista Electrónica de Geografía y Ciencias Sociales, 38, Barcelona, 1999. $<$ http://www.ub.edu/geocrit/sn-38.htm> [Consulta 29 de marzo de 2013].

Martínez, José Luis: «Relaciones y negociaciones entre las sociedades indígenas de la región atacameña, el Estado y la sociedad chilenos. Siglos XIX y XX», Proposiciones, 24, Santiago de Chile, 1994, 201-207.

Martínez, Nelson; Martínez, José Luis y Gallardo, Viviana: «Presencia y representación de los indios en la construcción de nuevos imaginarios nacionales (Argentina, Bolivia, Chile y Perú 1880-1920)», en Rojo, Grinor et al., 
Nación, Estado y Cultura en América Latina, Santiago de Chile, Ediciones Facultad de Filosofía y Humanidades Universidad de Chile, 2003, 191-222.

Mc Evoy, Carmen: «Chile en el Perú: guerra y construcción estatal en Sudamérica, 1881-1884», Revista de Indias, LXVI-236, Madrid, 2006, 195-216.

Muñoz Arbelaez, Santiago: «Medir y amojonar. La cartografía y la producción del espacio colonial en la Provincia de Santa Marta, siglo XVIII», Historia Crítica, 34, Bogotá, 2007, 208-231.

Navarro Floria, Pedro: «El salvaje y su tratamiento en el discurso político argentino sobre la frontera sur, 1853-1879», Revista de Indias, LXI-222, Madrid, 2001, 345-376.

Nogué i Font, Joan: Nacionalismo y territorio, Lleida, Editorial Milenio, 1998.

Oficina Central de Estadísticas: Sesto Censo Jeneral de la población de Chile levantado el 26 de noviembre de 1885, Valparaíso, Imprenta La Patria, 1886.

Oficina Central de Estadísticas: Sétimo Censo Jeneral de la población de Chile levantado el 28 de noviembre de 1895, Valparaíso, Imprenta Universo, 1900.

Ovalle, Francisco Javier: La ciudad de Iquique, Iquique, Imprenta Mercantil, 1908.

Penhos, Marta: «Indios del siglo XIX. Nominación y Representación», Las artes en el debate del Quinto Centenario, IV Jornadas de Teoría e Historia de las Artes, Buenos Aires, Centro Argentino de Investigadores de Arte, 1992, 188-195.

Pinto, Julio: «La sociedad tarapaqueña durante los primeros años de la ocupación chilena, 1879-1884», Nueva Historia, IV-15/16, Londres, 1995, 107-127.

Prakash, Gyan: «Los estudios de la subalternidad como crítica post-colonial», en Rivera Cusicanqui, Silvia y Barragán, Rossana (comps.), Debates postcoloniales: Una introducción a los estudios de la Subalternidad, La Paz, Ed. Historias/Ed. Aruwiyiri/SEPHIS, 1997, 293-313.

Quijada, Mónica: «Nación y Territorio: La dimensión simbólica del espacio en la construcción nacional argentina. Siglo XIX», Revista de Indias, LX-219, Madrid, 2000, 373-394.

Quijada, Mónica: «Repensando la frontera sur argentina: concepto, contenido, continuidades y discontinuidades de una realidad espacial y étnica (siglos XVIII-XIX)», Revista de Indias, LXII-224, Madrid, 2002, 103-142.

Rajchenberg, Enrique y Héau-Lambert, Catherine: «La frontera en la comunidad imaginada del siglo XIX», Frontera Norte, 19-38, Tijuana-México, 2007, 37-61.

Reyero, Carlos: «Pasivos, exóticos, vencidos, víctimas. El indígena en la cultura oficial española del siglo XIX», Revista de Indias, LXIV-232, Madrid, 2004, 721-748.

Rosenblitt, Jaime: «Economía, política y población en un espacio árido: el asentamiento humano en Tarapacá y sus ciclos históricos, 1536-2000», Mapocho, 62, Santiago de Chile, 2007, 275-297. 


\section{LUIS CASTRO CASTRO}

Sarti, Graciela y Rodríguez, Mariano: «Imagen de un "otro" para una nueva conquista. Transformaciones en la representación del indio en la iconografía del Río de la Plata. Siglo XIX», Las artes en el debate del Quinto Centenario. IV Jornadas de Teoría e Historia de las Artes, Buenos Aires, Centro Argentino de Investigadores de Arte, 1992, 215-218.

Turner, Frederick: The Frontier in American History, Charlottesville-VA, University of Virginia, 1996 [1893]. <http://xroads.virginia.edu/ HYPER/ TURNER/> [Consulta 8-10 de abril 2013].

Valcuende del Río, José y Cardia, Laís M.: «Etnografia das fronteiras políticas e sociais na Amazônia ocidental: Brasil, Peru e Bolívia», Scripta Nova. Revista Electrónica de Geografía y Ciencias Sociales, XIII-292, Barcelona, 2009. <http://www.ub.edu/geocrit/sn/sn-292.htm> [Consulta 2 de abril de 2013].

Vidal Gormaz, Francisco: Noticias del desierto y sus recursos, Santiago de Chile, Imprenta Nacional, 1879.

Villalobos, Sergio; Silva, Osvaldo; Silva, Fernando y Estellé, Patricio: Historia de Chile, Vol. 4, Santiago de Chile, Editorial Universitaria, 1976. 
Anuario de Estudios Americanos, 71, 2

Sevilla (España), julio-diciembre, 2014, 661-690

ISSN: 0210-5810. DOI: 10.3989/aeamer.2014.2.10

\section{Fe de erratas}

\section{Página 661}

Donde dice:

\section{Luis Castro Castro}

Universidad de Valparaíso, Chile

Debe decir:

\section{Luis Castro Castro}

Universidad de Playa Ancha Universidad de Valparaíso, Chile 